\title{
El consumo de la población de Tijuana, Baja California. Aplicación de un estudio de corte transversal
}

\author{
Alejandro Mungaray Lagarda \\ Facultad de Economía \\ Universidad Autónoma de Baja California
}

\begin{abstract}
Resumen
Los aspectos más relevantes de esta investigación abordan el aspecto del gasto en consumo a partir de una breve discusión teórica y de una presentación empírica de los resultados agrupados y analizados a través de regresión por mínimos cuadrados, con el fin de observar el grado en que el gasto en consumo es explicado por el ingreso en los distintos estratos urbanos de la población de Tijuana, B.C. Los estudios de ingreso-gasto resultan de gran importancia para observar el estado que guarda la distribución del ingreso y la estructura social del gasto en consumo en un espacio y tiempo específico. Por tal razón, este estudio está apoyado en una encuesta socio-demográfica de ingreso-gasto mediante un muestreo aleatorio realizado a partir de la división de la población, según el estrato urbano que habita. Se puede concluir que algunos estratos de la población en Tijuana soportan los precios locales, mientras las presiones inflacionarias no disparen la diferencia surgida por el tipo de cambio, y resulte mejor volver al comercio estadounidense como una forma de proteger su ingreso.
\end{abstract}

Palabras clave: consumo, consumidor, ingreso-gasto, estratos urbanos, bienes consumibles.

\begin{abstract}
The most outstanding content of this article is the research on consumption expenses that starts from a brief theoretical discussion and the empirical presentation of its results. These results will be grouped and analyzed through a minimal squares regression system. Its purpose is to observe how the degree on the consumption expenses is explained by observing the income of the diverse urban population strata from Tijuana Baja California. For this reason, a socio-demographic survey supports this project, by taking a random sampling after dividing the population according to their social position. As a conclusion, we can say that in Tijuana, some social groups are able to support local prices; instead of going back the American side stores in an attempt to protect their income; but they will only do it if the inflationary pressures do not trigger the difference resulting from dollar exchange rates.
\end{abstract}

Keywords: consumption, consumer, income-expenses, urban strata, consumable assets. 


\title{
EL CONSUMO DE LA POBLACION DE TIJUANA, BAJA CALIFORNIA. APLICACION DE UN ESTUDIO DE CORTE TRANSVERSAL
}

\author{
Por \\ Alejandro Mungaray Lagarda*
}

\section{INTRODUCCION}

Los estudios de ingreso-gasto resultan de gran importancia para observar el estado que guarda la distribución del ingreso y la estructura social del gasto en consumo en un espacio y tiempo específico. Por tal razón, en junio de 1984 se aplicó una encuesta sociodemográfica de ingreso-gasto mediante un muestreo aleatorio realizado a partir de la división de la población, según el estrato urbano que habita.

Los resultados más relevantes que se presentan de esta investigación, abordan el aspecto del gasto en consumo a partir de una breve discusión teórica y de una presentación empírica de los resultados agrupados y analizados a través de regresión por mínimos cuadrados, con el único fin de observar el grado en que el gasto en consumo es explicado por el ingreso en los distintos estratos urbanos de la población de Tijuana, B.C.

\section{ANTECEDENTES TEORICOS}

\section{Consumo y comportamiento del consumidor}

En el estudio del comportamiento del consumo se hace necesario distinguir dos niveles: el que se observa a nivel microeconómico, a nivel de productos individuales, y el que ocurre a nivel macroeconómico, que requiere de una observación más a nivel de las unidades familiares.

El comportamiento del consumidor individual sigue las pautas de los precios y las cantidades de un producto determinado. De otra forma, se expresa en una función de demanda que se mueve en relación inversa a los precios para cada bien particular. ${ }^{1}$ Por el contrario, el comportamiento del consumo como variable macroeconómica indicativa de cierto nivel de bienestar social, sigue las pautas del ingreso y se expresa en una función de consumo que se mueve en función de las decisiones de con-

\footnotetext{
- Profesor.Investigador de la Facultad de Economía, Universidad Autónoma de Baja California.

'Barokas, Rifat y Vargas, Alvaro E. "Estudio de mercado y comercialización", Curso sobre formulación y evaluación de proyectos. México, FONEP, 1981. pp. 38-9; Diulio, Eugene. Macroeconomía, México, MeGraw Hill (Schaumm). 1981. p. 51.
} 
sumo y ahorro $\mathrm{y}$, por tanto, de las proporciones que éstas signifiquen dentro del ingreso disponible. ${ }^{2}$

Aunque es evidente que el consumo de los distintos productos individuales está estrechamente relacionado con el comportamiento del consumo de las familias, también lo es el hecho de que existe una brecha cuantitativa y cualitativa entre ambos. Esta resulta de un cambio en el ingreso disponible de los distintos sectores de la población, que afecta el comportamiento de los dos niveles de consumo, bien sea por cambios absolutos uniformes, o provenientes de cambios en la distribución del ingreso. Al respecto, Hicks señaló acertadamente que no es necesario que un incremento en el ingreso tienda a incrementar la demanda de cada bien particular del consumidor. Es posible que haya algunos bienes cuyo consumo disminuya para ser reemplazado por sustitutos superiores, cuando se elevó el ingreso. ${ }^{3}$ Esta sustitución obedecería al criterio del equilibrio del consumidor en el mercado, cuando la utilidad marginal de cada bien sea proporcional a su precio; esto es, cuando la utilidad marginal de cada bien sea igual al precio de cada bien multiplicado por la utilidad marginal del dinero. ${ }^{4}$

Como se ve, en tanto que los efectos de las variaciones del ingreso sobre el comportamiento de los bienes individuales se miden en términos de las variaciones de la demanda que ocurre por ellos, las mismas variaciones del ingreso en el comportamiento del consumo de las familias se miden en términos de las variaciones de las proporciones destinadas al consumo y al ahorro respecto al ingreso total. Por tanto, para observar el consumo como un fenómeno social, es necesario hacerlo desde una panorámica macroeconómica; no obstante que sea un hecho conocido y aceptado que las principales teorías del consumo, como la del ciclo vitalicio de Ando-Modigliani, la del ingreso permanente de Friedman y la del ingreso relativo de Duesenberry, se basan en la teoría microeconómica de la preferencia del consumidor. La razón fundamental para considerar esta teoría como el punto de partida en la formulación de teorizaciones macroeconómicas acerca del comportamiento del consumo, descansa en la aceptación de la racionalidad de la conducta del consumidor como factor que permite un orden sistemático de preferencias, en virtud del cual realiza elecciones entre el conjunto de alternativas que constituyen los elementos de las canastas de mercancías, dados los precios de éstas y el tamaño de su presupuesto. Esta idea resulta de fundamental importancia, pues valida o cuestiona un sistema económico en virtud de que la eficacia de éste debe medirse

\footnotetext{
${ }^{2}$ Keynes, J.M. La teoría general de la ocupación, el interés y el dinero, México, FCE, 9a. reimp. 1979. Caps. 8 y 9; Hansen, Alvin, Guía de Keynes, México, FCE. 6a. reimp. 1978: libro III; Dillard, Dudley, La teoría económica de John Maynard Keynes, Madrid, Aguilas, 9a. ed. 1971.

3 Hicks, J.H., Revisión de la teoría de la demanda, México, FCE. 1958. p. 82.

I Ibid. p. 22
} 
por su capacidad de respuesta a las preferencias de todos los estratos y/o niveles de consumidores.

\section{La función consumo y los enfoques existentes}

En lógica consecuente, cabe preguntarse ¿qué condiciones permiten hacer funcional el examen de la conducta racional de los consumidores en términos de una función que exprese cierto nivel de realismo y sea empíricamente constrastable? Para responder y puntulizar esto, es necesario retomar los distintos argumentos vertidos acerca del comportamiento del consumidor.

En Keynes, la proporción del ingreso destinada al consumo y su expresión en una función, necesariamente se encuentra referida a un nivel de ingreso en términos de unidades de salarios (Ys) que corresponderán a un nivel dado de ocupación $(\mathrm{N})$. Por lo tanto, la propensión a consumir será una relación funcional cualquiera $(X)$ entre el nivel de ingreso medido en unidades de salario ( $\mathrm{Ys}_{\mathrm{s}}$ y el gasto que para consumo se destina de dicho nivel (Cs). Esta situación es expresada formalmente en Keynes como: $\mathrm{Cs}_{\mathrm{s}}=\mathrm{X}(\mathrm{Ys}) .{ }^{5}$ Sin embargo, a partir de entonces ha ocurrido un perfeccionamiento en los argumentos explicativos de la función de consumo, que han resultado en planteamientos más elaborados.

En términos generales, la tradición keynesiana afirma que "al aumentar el ingreso la gente tiende a gastar un porcentaje cada vez menor de sus ingresos, o por el contrario, se inclina a ahorrar un porcentaje cada vez mayor de ingreso"6; esto es, al decir de Heilbroner, a liberar recursos del consumo, lo que no significa destinarlos a la inversión ya que ésta sólo ocurre cuando dichos recursos se utilizan en la formación de capital. ${ }^{7}$

Esta afirmación dio origen a la idea de que dado un patrón de consumo, al incrementarse el ingreso, la proporción del mismo ahorrado, aumentará de la misma manera que la razón de demanda de consumo al ingreso, disminuirá de manera indefinida, llevando a una situación de estancamiento que se resolvía, se pensaba, a través del incremento del gasto público, ya que si éste "no aumenta a una tasa más rápida que el ingreso, la economía no crecería, sino que se estancaría" en virtud del escaso crecimiento del consumo. ${ }^{8}$

Esto resulta de una fidelidad interpretativa extrema de las afirma-. ciones keynesianas, ya que durante la posguerra, la liberación de los recursos de los consumidores ahorrados forzadamente ante la situación bélica, impugnó la validez de las afirmaciones keynesianas, por lo menos

\footnotetext{
S Keynes, J.M. Op. cit. pp. 87-88.

6 Branson, W.H. Teoría y política macroeconómica, México, FCE. 1981. p. 242.

${ }^{7}$ Heilbroner, Robert. The Making of Economic Society, Englewood Cliffs, Prentice Hall. 1962.

Branson, W.H. Op. cit., 1981. p. 244.
} 
en lo que se refería al largo plazo, ya que se observó que si bien en el corto plazo el gasto en consumo aumentaba en proporción crecientemente menor que el ingreso ante un aumento de éste, en el largo plazo, el consumo tendía a aumentar en mayor proporción que lo observado ante incrementos en el ingreso. ${ }^{9} \mathrm{Al}$ respecto existen variados intentos explicativos que van desde el "ingreso relativo" de Duesenberry y el "ingreso permanente" de Friedman, hasta el papel de los activos reales de los consumidores y en el ingreso corriente de Ando y Modigliani.

En efecto, Duesenberry sostiene dos hipótesis básicas en la explicación del comportamiento del consumo: la primera afirma que "los consumidores no atribuyen tanta importancia a su nivel absoluto de consumo como a su consumo en relación con el resto de la población. ${ }^{10} \mathrm{De}$ otra forma, las decisiones de consumo y ahorro de los consumidores están fuertemente influenciadas por el ambiente social en que viven. Esto implicaría que un individuo que goza de un nivel de ingreso dado, consume más si vive en un vecindario rico que en uno pobre. Por tanto, si la distribución del ingreso es relativamente constante, la propensión media al consumo de un individuo será relativamente constante, ya que su consumo guarda relación con su ingreso relativo dentro de la comunidad, y no con su nivel de ingreso absoluto. ${ }^{11}$

La segunda hipótesis afirma que "el consumo presente no [sólo] es afectado (de manera simple) por los niveles presentes de ingreso absoluto y relativo, sino también por los niveles de consumo alcanzados en los períodos previos". ${ }^{12}$ Mas simplemente, esto significa que a las familias les gusta mantener un determinado nivel de vida, por lo que su función consumo se presenta como $\mathrm{C}=\mathrm{F}$ (Ye, Ypp), donde $\mathrm{Ye}$ es el ingreso corriente y Ypp el máximo ingreso previo. Así, si el ingreso corriente es mayor que el ingreso previo ( $\mathrm{Ye}>\mathrm{Ypp}$ ), el consumo guardará una relación favorable con el ingreso relativo del individuo dentro de la comunidad. Si por el contrario, el ingreso corriente es menor que el ingreso previo (Ye $<\mathrm{Ypp}$ ), el consumo guardará una relación favorable con el ingreso previamente establecido.

Por su parte, con su teoria del ingreso permanente, Friedman trata de resolver la relación entre consumo e ingreso disponible, a partir de afirmar que el nivel de consumo no descansa sobre la base del nivel corriente de ingreso disponible ( $\mathrm{Ym}$ ), debido a que éste se compone por un ingreso que es permanente ( $\mathrm{Yp}$ ) y un ingreso que es transitorio ( $\mathrm{Yt}$ ), y que el nivel de consumo no se determina por ambos sino por el ingreso permanente, que se compone del nivel de ingreso que las familias esperan recibir en un período de varios años. ${ }^{13}$ Para afirmar lo anterior,

9 Diulio, Eugene. Op. cit. p. 56.

${ }^{10}$ Branson, W.H. Op. cit., 1981. p. 265.

11 Diulio, Eugene. Op. cit., 1981. p. 57.

${ }^{12}$ Branson, W.H. Op. cit., 1981. p. 266.

${ }_{13}$ Diulio, Eugene. Op. cit., 1981. pp. 57.8. 
Friedman supone "que no hay relación entre el consumo permanente y el transitorio, de tal manera que este último es sólo una variación aleatoria alrededor del primero". Esto significaría que un "aumento repentino del ingreso debido a una fluctuación transitoria no contribuirá inmediatamente al consumo del individuo". 14

Tras este argumento del ingreso permanente, se encuentra la crítica al argumento keynesiano de "que el gasto en consumo presente es una variable que depende en alto grado [... . ] de la renta presente", ya que la experiencia de la posguerra subrayó el "carácter inadecuado de una función de consumo que relacione el consumo o el ahorro solamente con la renta presente" y destacó la importancia de "ofrecer una explicación [. . . ] de la elevada relación consumo-renta" a partir de su íntima correlación con la relación riqueza-renta. ${ }^{15}$. Esto significa que Friedman descansa su teoría del consumo en el nivel de ingreso permanente de los individuos, ya que ello le permite explicar el comportamiento de la relación entre el consumo y el ingreso en función de la relación existente entre la riqueza y el ingreso de los mismos. Por ende, su explicación del consumo descansa en el nivel de ingreso permanente y no en el nivel de ingreso transitorio.

La hipótesis del ciclo vitalicio de Ando y Modigliani sugiere que "en los primeros años de su vida, el individuo es un prestatario neto. En los años intermedios ahorra para cubrir sus deudas y tener provisiones para el retiro y en los últimos años [. . .] desahorra". Esto permite a los autores de la hipótesis relacionar la corriente de ingresos de los individuos con el nivel de productividad alcanzado en las distintas etapas de su vida. Así, al principio y al final, la productividad será poca, en tanto que a la mitad será alta. A nivel global, esto significaría que en una muestra de la población clasificada por nivel de ingresos, "los grupos de ingresos elevados incluirán una proporción" de ingreso ahorrado más alto "que el promedio de personas que se encuentran en los niveles de ingreso inferiores, porque están en los años intermedios de la vida y, por tanto, tienen una proporción del ingreso gastado en consumo (c/y) relativamente baja. De modo similar, los grupos de ingresos bajos comprenderían relativamente a más personas cuyos ingresos son reducidos debido a que se encuentran en los extremos de la distribución por edades y, consecuentemente, tienen una proporción del ingreso gastado en consumo (c/y) mas alta".16

La virtud de Ando y Modigliani es que, aprovechando las experiencias de lo que Hansen llama "tendencia secular alcista en la función consumo" observada a partir de la posguerra, ${ }^{17}$ empiezan a hacer

14 Branson, W.H. Op. cit., 1981. p. 261.

is Friedman, Milton. "La general theory como estímulo para la investigación económica", en Lekachman 1983.

16 Branson, W.H. Op. cit., 1981. p. 252.

${ }^{17}$ Hansen, Alvin. "La función de consumo como contribución a la teoría económica", en Lekachman 1983. p. 92. 
operacional el término "valor presente", observando que el ingreso puede dividirse, a diferencia de Duesenberry y Friedman, en ingreso por trabajo $\left(\mathrm{Y}^{\mathrm{L}}\right)$ e ingreso por activos de propiedad $\left(\mathrm{Y}^{\mathrm{P}}\right)$.

Así, mediante una serie de transformaciones derivadas de la distinción que hacen del ingreso; de su conversión en términos de valor presente; y del hecho de que el consumo esté en función del valor presente del ingreso, Ando y Modigliani entregan una función de consumo que depende tanto del ingreso proveniente del trabajo como de los activos de la siguiente forma: $\mathrm{C}=\varsigma 0 \mathrm{Y}^{\mathrm{L}}+\alpha$ a donde $\mathrm{Y}^{\mathrm{L}}$ es ingreso por trabajo y "a" es el ingreso por activos, considerando "que el valor presente del ingreso de un activo es igual al valor del activo mismo, medido al principio del período corriente". Los parámetros $\mathcal{L}_{0}$ y $\alpha^{\alpha}$ se refieren a las magnitudes de las proporciones marginales a consumir del ingreso corriente y del ingreso por activos.

La ventaja que presenta este modelo respecto a los otros es que, en tanto que Friedman y Duesenberry contemplan de manera implícita los activos como un determinante del "ingreso permanente" y del "máximo ingreso previo", y por tanto, descansan su observación en aspectos menos observables, Ando y Modigliani destacan claramente los aspectos observables en ingreso por trabajo y en valor de los activos. ${ }^{18}$

Como se señaló, el papel de los activos líquidos resulta de fundamental importancia en la explicación de la tendencia al alza de consumo y en el entendimiento de por qué el comportamiento del consumo no es igual en el corto y largo plazo como lo supuso Keynes; ni por tanto sea absolutamente indispensable que un gasto deficitario se instrumente subsidiando precios o inversiones con el expreso objeto de evitar la caída de la demanda global por la supuestamente inevitable caída de la demanda de consumo respecto al ingreso. Por lo menos no en los términos planteados, aunque una política de gasto deficitario destinada a incentivar el consumo de activos, elevaría el consumo real estimulando con ello la inversión.

Esto permite deducir que si bien la formulación keynesiana acerca del comportamiento del consumo fue expresada en términos demasiado generales y absolutos, que no permitieron a los continuadores de la misma explicar las tendencias de largo plazo del consumo, el hecho de que se desagregara de la forma en que lo hacen Ando y Modigliani, permite darle continuidad a la teoría más que negarla, mediante una alteración de los resultados esperados en el largo plazo, sin que ello signifique dejar de lado la necesidad de una incesante participación del gasto público para mantener un adecuado nivel de demanda efectiva. De hecho, la participación estatal a través de programas de vivienda y de políticas de control de precios permiten, o bien incrementar el nivel de

10 Branson, W.H. Op. cit., 1981. pp. 253-2, 271, 253, 265. 
activos reales adquiridos o bien incrementar el nivel de ingreso disponible, incrementando con ello, y de manera global, el nivel de consumo real, permitiendo entender lo que Hansen quiere decir cuando afirma que un nivel de consumo mayor sigue a un nivel de ingreso creciente, y no al revés. ${ }^{19}$

\section{LA FUNCION CONSUMO Y SUS DETERMINANTES EN UN ESTUDIO DE CORTE TRANSVERSAL. METODO Y PROCEDIMIENTOS.}

Siguiendo las pautas iniciadas líneas atrás, una función consumo adecuada para indagar el comportamiento del consumo en relación de los ingresos, sería aquélla que considere el nivel de ingreso de los consumidores y el patrimonio expresado en activos. Sin embargo, es prudente involucrar otro tipo de condiciones que, aunque difícilmente observables y cuantificables, influyen de manera importante, como la publicidad, la posibilidad de obtención de crédito y las expectativas en el nivel de vida de los consumidores, ya que como señala Hansen, los factores subjetivos determinan la forma de la función. ${ }^{20}$ Esta forma es más o menos homogénea en el corto plazo, debido a que las variaciones en la propensión a consumir con un nivel de ingreso dado tienden a presentarse en el largo plazo, dependiendo la cuantía del consumo en el corto plazo, más que nada de las variaciones en el nivel de ingreso. Por esta razón, en su análisis de corto plazo, Keynes supuso que los factores subjetivos se conocen y que, por tanto, la propensión a consumir depende sólo de cambios en los factores objetivos como la unidad de salario, la diferencia entre ingreso e ingreso neto, la relación de cambio entre bienes presentes y futuros, la política fiscal, las expectativas acterca del nivel presente y futuro del ingreso, etcétera. ${ }^{21}$

Ahora bien, las condiciones bajo las que se puede obtener una función consumo estable de la comunidad son dos: o bien que todos los consumidores tengan la misma propensión marginal a consumir, ya que así los cambios ocurridos en la distribución del ingreso entre los consumidores no afectará el nivel de consumo total, o bien, que si los consumidores tienen una propensión marginal a consumir diferente, la distribución del ingreso entre ellos no varíe.

Para observar esto se puede disponer de datos estadísticos de corte transversal o series cronológicas. Las series cronológicas o temporales indican cómo han funcionado a lo largo del tiempo el consumo y el ingreso; en tanto que los datos de corte transversal, obtenibles a partir del estudio de presupuestos familiares derivados de una muestra de

\footnotetext{
19 Hansen, Alvin. Op. cit., 1983. p. 94.

${ }^{20}$ Hansen, Alvin. Guía de Keynes, México, FCE. 6a. reimp. 1978. p. 67.

${ }^{21}$ Keynes, J.M. Op. cit., 1981. p. 89-92.
} 
consumidores, indican cómo se relacionan en un momento cualquiera, los diferentes gastos de los consumidores con sus ingresos respectivos. De esta forma, los datos de corte transversal permiten observar cómo varía el consumo entre los distintos niveles observados en la distribución del ingreso, y no cómo varía el consumo cuando el ingreso de todos los individuos varía en el tiempo. ${ }^{22}$ Por tal razón, un estudio de corte transversal acerca del comportamiento del consumo, necesariamente se limita a conocer el comportamiento del gasto del consumidor según su posición en la escala de ingresos de la comunidad en estudio, y según los subcomponentes del consumo familiar. ${ }^{23} \mathrm{~A}$ mayor abundancia, existen dos tipos de ecuaciones: las de comportamiento, que son ecuaciones compuestas por variables dependientes, independientes y aleatorias susceptibles de mostrar cambios en el tiempo, y las de definición, que aunque son ecuaciones también susceptibles de cambios, se componen sólo de variables dependientes; esto es, variables previamente determinadas por variables dependientes y/o aleatorias. En consecuencia, en un estudio de corte transversal, lo esencial es determinar la estructura del gasto en consumo y no el comportamiento de éste en el tiempo a partir de un análisis de regresión, ya que desde un punto de vista econométrico, una ecuación de definición no permite un análisis completo de regresión debido a que al haber multicolinealidad, el coeficiente de correlación tiende a uno, y nunca las variables colocadas como independientes permiten explicar totalmente a las variables colocadas como dependientes; esto es, que las variables explicatorias son colineales o linealmente dependientes. ${ }^{24}$ Sin embargo, el análisis de regresión, con el objetivo de realizar una estimación de gastos autónomos y propensiones de consumo, sí es posible de realizar con una sola observación muestral, a partir de medir el cambio proporcional que ocurre en el consumo al pasar de un nivel a otro de ingreso. De otra forma, el cambio en el consumo de los distintos tipos de bienes considerados ante los cambios en la estructura del ingreso, sólo es válido en términos del momento histórico preciso, y no para estimar tendencias. ${ }^{25}$

Por otra parte, estudios que descomponen el gasto en consumo destinado a bienes de consumo perecederos (BCP) y a bienes de consumo duraderos (BCD), han mostrado que gran parte de la inestabilidad existente en el consumo a corto plazo, ocurre en estos últimos, ya que en su

22 Lipsey, Riehard G. Introducción a la economía positiva, Barcelona, Vicens.Vires, 9a. ed, 1974. p. 544-6.

${ }^{23}$ Lustig. Nora. Distribución del ingreso y crecimiento en México. Un análisis de las ideas estructuralistas. México, El Colegio de México. 1981. p. 24.

24 Sabau, Hernán. El método econométrico. Una visión intuitiva, México, C1DE. 1982.

${ }^{25}$ Cortés, Fernando. Algunos problemas de formalización y estimación de modelos de regresión con variables cualitativas aplicadas a la investigación social, Mèxico, El Colegio de México (Cuadernos del CES 29), 1981. p. 37; Edwards, Allen L. An introduction to linear regression and correlation, San Francisco, W.H. Freeman Company. 1976. Caps. 1.4. 
compra influyen el tipo de interés, el tamaño del primer pago y las expectativas de cambio en el ingreso; factores que no influyen en la compra de los primeros. Por esta razón, un estudio de corte transversal acerca del comportamiento del consumo, tiene que considerar de manera obligada, la riqueza previamente acumulada de los consumidores; observable sobre todo a partir del tipo de consumo que realizan los distintos estratos de ingreso. Al respecto, se utiliza el esquema de subcomponentes del consumo en función de los distintos estratos del ingreso, propuesto por Lustig, con la inclusión de algunas variables que permitan cuantificar la riqueza patrimonial, pues parece ser el más indicado para analizar el comportamiento del consumo en un estudio de corte transversal, en el contexto de una estructura socioeconómica del ingreso específica como lo es la de Tijuana, Baja California.

La información pertinente ha sido recabada mediante una encuesta de ingreso-gasto aplicada por muestreo aleatorio. Para ello, se seleccionó la unidad familiar como núcleo muestral y se dividió la ciudad en tres distintos sectores urbanos: el estrato urbano marginal, compuesto por familias que habitan en zonas sin pavimento, con luz, agua (depositada por camión pipa); sin teléfono, con habitación de madera, o cartón predominantemente, sin emplaste; sin comercios variados y con transporte irregular. El estrato urbano medio, compuesto por familias que viven en zonas con pavimento, luz, agua entubada, drenaje y con un mínimo de teléfonos de $10 \%$, habitaciones de material, comercios variados y con transporte vario y regular; y por último, el estrato urbano privilegiado, donde habitan familias que cuentan con zonas pavimentadas, luz, agua entubada, drenaje, alumbrado mercurial, teléfono, habitaciones con prototipo residencial y materiales de primera; vías de acceso excelentes y zonas comerciales cercanas. Posteriormente, se definieron las colonias en el plano de distribución urbana de SAHOPE*, tipificadas según el estrato urbano a que pertenecían a partir de su criterio y el propio obtenido de múltiples visitas y observaciones, y se procedió a su cuantificación, para posteriormente proceder a determinar una muestra aleatoria por estrato, aplicando la tabla de números aleatorios de L.H.C. Tippett, conforme procedimiento común. ${ }^{26}$ Así se seleccionaron las colonias más representativas por estrato, y después se contabilizaron progresivamente para aplicar de nueva cuenta la tabla de números aleatorios y seleccionar un mínimo de $10 \%$ de colonias por estrato, lo que permitió distribuir porcentualmente la aplicación de 2,038 cuestionarios.

Por su parte, la encuesta ha sido diseñada pensando en capturar la mayor cantidad posible de información para cuantificar, en distintos niveles, el ingreso y el gasto. Dada la escasa movilidad de los elementos

- Secretaría de Asentamientos Humanos y Obras Públicas del Estado.

${ }^{26}$ Sukhatme, Pandurang V. Teoría de encuestas por muestreo con aplicaciones, México, FCE. $2 \mathrm{a}$. ed. 1962. p. 6-7. 
que determinan el ingreso, éste ha sido cubierto con once preguntas, en tanto que la estructura del gasto ha sido cubierta con 195.

\section{COMPOSICION DEL GASTO EN CONSUMO POR TIPO DE PRODUC- TOS, NIVEL DE INGRESO Y ESTRATO URBANO. RESULTADOS E INFERENCIAS}

Las orientaciones de los consumidores tijuanenses hacia los distintos tipos de productos varían según su nivel de ingreso y según el estrato urbano en que se ubican, de tal forma que se pueden observar diferencias e inequidades derivadas de la peculiar distribución del ingreso. En lo que sigue, a partir de indicadores sobre gasto familiar mensual y estructura porcentual del gasto, así como de un análisis de regresión simple, se trata de observar las características de la distribución del gasto en consumo según el nivel de ingreso y el estrato urbano perteneciente, así como los posibles cambios que ocurrirían en la estructura del consumo a partir de los cambios en la estructura del ingreso, sobre la base de estimaciones porcentuales no válidas para obtener tendencias y comportamientos con alto nivel de confianza.

\section{Bienes perecederos primarios.}

Estos están constituidos por todos aquellos bienes que no pertenecen a las ramas manufactureras, lo que significa en este caso, todos los granos, las frutas, las verduras y los alimentos de origen animal que acaparan un gasto familiar promedio de 28,753 pesos mensuales en las familias del estrato urbano privilegiado, y de 26,757 y 20,384 pesos mensuales, respectivamente, en los estratos urbanos medio y marginal. Debe notarse, sin embargo, que estas magnitudes absolutas de gasto de las familias de los distintos estratos, significan magnitudes relativas que siguen un comportamiento inverso al anotado, ya que el monto mayor de gasto promedio de las familias del estrato urbano privilegiado representa una proporción menor del gasto en consumo de éstas, pues sólo significa el $22 \%$ del mismo, en contraposición a un gasto mensual promedio de las familias de los otros estratos que es menor y que significa una proporción mayor del mismo con 30.2 y $30.7 \%$ respectivamente.

Por otra parte, en el estrato urbano privilegiado, las familias que tienen un gasto en consumo mayor que el promedio, son las que se ubican en los niveles de ingreso que van hasta dos veces el salario mínimo, y los que perciben de 14 a más veces dicha cantidad, en tanto que en los estratos urbanos medio y marginal, todas las familias, excepto las de ingreso que van de menos y hasta dos veces y hasta una vez el salario mínimo respectivamente, gastan en consumo de bienes perecederos primarios arriba del promedio gastado en dichos bienes. 
Las características principales del gasto en consumo de las familias que perciben desde dos y hasta cuatro veces el salario mínimo, es que en todos los casos, el gasto de las familias del estrato urbano medio es mayor que el de las familias de los otros estratos, aunque el de las familias del estrato urbano privilegiado es mayor que el de las familias del estrato marginal, salvo en el caso de las que perciben de 11.5 a 14 veces, en que las familias de este último estrato urbano gastan un promedio de 28,163 pesos mensuales en básicos, en contraposición a 26,222 en el estrato urbano privilegiado.

Esto es indicativo de dos cosas: en primer lugar, de que en virtud de un gasto en consumo menor en bienes perecederos primarios por parte de las familias del estrato urbano marginal, es factible pensar en insuficiente nivel nutricional de las mismas, aunque no haya estudios precisos al respecto, salvo las que se ubican en los niveles de ingreso que van de 11.5 a más veces el salario mínimo, ya que tienen niveles absolutos de gasto similares a los de las familias del estrato urbano privilegiado, y las de niveles de ingreso superiores a dos veces el salario mínimo que habitan en el estrato urbano medio. En segundo lugar, que las insuficiencias nutricionales en la alimentación de las familias de los estratos urbanos marginal y medio, salvo las del nivel de ingreso de 6.5 a 9 veces el salario mínimo y las del nivel de ingreso que va de 6.5 a 11.5 veces en el estrato urbano medio, pese a que destinan aproximadamente la tercera parte de su gasto en consumo a su obtención, en detrimento de su acceso a otro tipo de bienes que contribuirían a su bienestar económico y social, ocurren debido al acuciante incremento de los precios en este tipo de bienes de consumo básico.

Es importante hacer notar, que tras de realizar un análisis de regresión simple, resulta que el gasto en consumo autónomo de este tipo de bienes varía a nivel de cada estrato urbano particular; es decir, el gasto mensual que se realiza con independencia de los cambios observados en el nivel de ingreso de las familias del estrato urbano privilegiado, es mayor que el gasto en consumo promedio; lo que significaría que ante cambios en la distribución del ingreso que aumentaran los niveles absolutos del mismo, no ocurrirían incrementos en el gasto en consumo de estos bienes, pues es muy probable que ya se realice por transferencias de ingresos o por ingresos adicionales no declarados. Por tal razón, el gasto en consumo de bienes perecederos primarios, realizado por las familias de este estrato, no es explicado de manera importante y significativa por el ingreso, debido a que el gasto en consumo mensual autónomo de bienes perecederos primarios es igual a $29,286.84$ y, por tanto, mayor que el gasto en consumo promedio mensual en bienes perecederos primarios que es igual a 28,753.00, y donde los parámetros de la ecuación son mayores del .25 de significancia, lo que disminuye su confiabilidad. ${ }^{27}$

" Kim, Jae-On y Kohout, Frank J. "Multiple regression analysis; subprogram regression", varios, SPSS. Statistical package for the social sciences, Chicago, McGraw Hill, 2a. ed. 1981. 
Por el contrario, el gasto mensual autónomo en consumo de bienes perecederos primarios realizado por las familias de los estratos urbano medio y marginal, es menor que el gasto promedio mensual observado, ya que en el primer caso es de $25,211.20$ pesos contra $26,757.00$, y en el segundo, de 20,350.15 contra 20,384.00 pesos mensuales. Lo indicativo de estos datos es que, aunque el incremento del gasto en consumo de estas familias ante incrementos en el nivel de ingresos por una mejor redistribución del mismo sería positivo, este incremento sería mayor en las familias del estrato urbano medio, que tienen una propensión marginal a consumir de $2.5 \%$, que en las familias del estrato urbano marginal cuya propensión marginal a consumir es de $2.2 \%$ y donde el grado de determinación $\left(\mathrm{r}^{2}\right)$ del gasto en consumo de estos bienes por el nivel de ingreso, es de 63 y $54 \%$, y el de correlación ( $r$ ), o grado en que la variable dependiente (gBPPEUMe y gBPPEMa) es explicada por la independiente ( $\mathrm{Y}=$ ingreso promedio), es de 79 y $73 \%$ respectivamente, con un nivel de significancia del .05 , lo que indica que los parámetros de las ecuaciones son confiables al $95 \%$.

\section{Bienes perecederos tradicionales.}

Estos bienes están constituidos por todos aquellos alimentos elaborados o semielaborados con métodos manufactureros, tales como harina de trigo y de maíz; alimentos en conserva, aceites y grasas comestibles; otros alimentos y bebidas; bebidas alcohólicas, cigarros y tabacos, y absorben un gasto familiar promedio de $14,045,13,059$ y 9,959 pesos mensuales en cada uno de los citados estratos urbanos en el orden acostumbrado. Este gasto representa a su vez el $10.8,14.7$ y $15 \%$ respectivamente, del gasto promedio en consumo total que realizan las familias de los mismos estratos urbanos.

Es relevante que en términos generales, la proporción de gasto en consumo en estos bienes realizada por las familias en todos los casos, signifique cerca del $50 \%$ del realizado en bienes alimenticios perecederos primarios, y que el gasto en su consumo siga el mismo comportamiento que el realizado en el de bienes perecederos primarios; ya que visto por nivel de ingreso, el gasto de los que perciben desde menos y hasta dos veces el salario mínimo, tiene una trayectoria descendente conforme se pasa del estrato urbano privilegiado al marginal. A la vez, sólo las familias de estos niveles de ingreso y las de los que van de 11.5 a más veces el salario mínimo, gastan en el consumo de estos bienes una cantidad mensual mayor al promedio en el caso del estrato urbano privilegiado; en tanto que en el medio, sólo las familias de los menores niveles de ingreso gastan por abajo del promedio; y en el marginal sólo los que ganan menos y hasta el mínimo, lo hacen por abajo del promedio. 
Por otra parte, pese a que el gasto en consumo de las familias de este último estrato que perciben entre 11.5 y 14 veces el salario mínimo es mayor que el que realizan las familias del mismo nivel de ingreso en los otros estratos, la proporción que tal cantidad significa dentro de su gasto en consumo total es mucho mayor, ya que todo parece indicar que las familias de los estratos privilegiado y medio, canalizan un mayor gasto al consumo de otro tipo de bienes, principalmente duraderos modernos; lo que presupone que el consumo de las familias de altos ingresos de otros estratos urbanos se encuentra sumamente ligado, por costumbre o por que ello acarrea mayor prestigio social a los patrones de consumo norteamericanos, en contraposición al gasto en consumo de las familias de altos ingresos del estrato urbano marginal, que se destina en alto grado al consumo de bienes alimenticios y de aseo y vestido personal, debido muy probablemente a hábitos y costumbres diferentes que provienen de niveles y patrones culturales diferentes.

A mayor abundancia, cabe agregar que ante cambios en el ingreso que mejorara su distribución dentro del estrato urbano privilegiado, probablemente se observarían cambios en el gasto en consumo de bienes perecederos tradicionales, ya que la propensión marginal a consumir es negativa e igual a -.6\% y su consumo autónomo de 14,933.71 pesos mensuales, ligeramente superior al gasto en consumo familiar promedio mensual de $14,045.00$ pesos, donde $\mathrm{r}^{2}=.03 \mathrm{y} \mathrm{r}=.18$, lo que indica que el gasto en consumo no es suficientemente explicado por el ingreso, y que por tanto la significancia es reducida. Por el contrario, el consumo autónomo en bienes perecederos tradicionales que realizan las familias de los estratros urbanos medio y marginal, es menor que el consumo promedio observado; ya que en el primero es de $12,373.21$ contra 13,059.00 pesos mensuales y, en el segundo, de $9,446.25$ contra 9,959.00 pesos mensuales; lo que quiere decir que ante cambios en la distribución del ingreso que mejoraran su distribución, estas familias incrementarían su gasto en consumo en 1.2 y $2.1 \%$ respectivamente, en virtud de que el gasto en consumo que realizan las familias de estos estratos en este tipo de bienes, está explicado por el nivel observado de ingreso en un 82 y $81 \%$ respectivamente, siendo los parámetros de ambas significativos al nivel de .01; esto es, válido al $99 \%$.

\section{Bienes duraderos tradicionales}

Estos bienes se constituyen por prendas de vestir y calzado; cosméticos, jabón, papel higiénico, pasta dental, toallas de baño, shampoo; artículos para el aseo de calzado y para aseo del hogar como detergente y escobas, mismos que absorben un gasto familiar promedio de $26,518.00$ pesos mensuales en el estrato urbano privilegiado y de $15,948.00$ y 19,826.00 pesos mensuales en los estratos urbanos medio y marginal, que 
representan a su vez, el $20.3,18$ y $18.3 \%$ respectivamente, del gasto promedio mensual en consumo total.

Resulta muy relevante, que en todos los casos el gasto en consumo autónomo sea menor que el gasto mensual promedio de las familias de los distintos estratos urbanos en dichos bienes; ya que en tanto las familias del privilegiado tienen un consumo autónomo de $\mathbf{2 4 , 0 6 9 . 2 5}$ pesos, tienen a la vez un consumo promedio de $26,518.00$, lo que significaría que las familias de los rangos de ingreso que van de uno a tres, de cuatro a nueve y de 11 a 14 veces el salario minimo, que gastan en menor cantidad que el consumo autónomo, sólo responderían con pequeños incrementos en el gasto en consumo de dichos bienes ante cambios en la estructura distributiva del ingreso, puesto que la propensión marginal a consumir dichos bienes es de $1.3 \%$.

Esta respuesta en el gasto en consumo de bienes duraderos tradicionales, ante cambios en la distribución del ingreso, sería mejor en el caso de las familias del estrato urbano medio y marginal, que responderían con un incremento de 3.6 y $3.5 \%$ respectivamente, ya que aunque el consumo autónomo es menor que el promedio, sólo las familias que perciben hasta el salario mínimo en ambos casos tienen un gasto en consumo menor que el autónomo, lo que significaría que ante cambios en la estructura distributiva del ingreso, estas familias incrementarían en manera importante su gasto en consumo de estos bienes.

Ahora bien, el carácter de "no sumamente necesario" de muchos de estos bienes, arroja extrañas inferencias sobre la disponibilidad a gastar en su consumo; ya que, en tanto en el estrato urbano privilegiado este consumo apenas es explicado por la estructura observada del ingreso en $31 \%$, en los estratos urbanos medio y marginal, el mismo consumo es determinado por la estructura del ingreso en 78 y $91 \%$ y explicado en 88 y $\mathbf{9 5 \%}$ respectivamente, lo que pudiera significar que los altos consumos de las familias que perciben de 4 a 14 y más veces el salario mínimo en el estrato urbano medio y marginal en bienes de aseo e higiene personal, son altamente significativos para explicar el comportamiento de dicho gasto en consumo dentro de su respectivo sector, debido a la importancia que la higiene del hogar tiene para todos ellos, mostrando niveles de significancia similares a los del caso anterior.

\section{Bienes duraderos modernos}

Los bienes que aquí se consideran, son todos aquellos productos manufacturados por la industria de bienes duraderos de consumo final como son lavadoras para ropa, muebles para sala, comedor, recámaras, plancha, refrigerador, batería para cocina, estufa, televisión, ventilador y cooler y otros enseres, mismos que por las condiciones especiales de su compra, que no es un acto cotidiano, relacionado con facilidades de pago 
en el tiempo y expectativas futuras en el nivel de ingreso, absorben gastos promedios mensuales que son similares a los que se podría llamar como abonos y que significan en el estrato urbano privilegiado un monto de $11,393.00$ pesos mensuales en promedio por familia, contra 6,091.00 y $3,918.00$ pesos en los otros estratos, mismos que representan proporciones contrarias respecto al gasto total en consumo como se ha venido observando; aunque tampoco muestran diferencias sustanciales, ya que en tanto los $11,393.00$ pesos significan el $8.7 \%$ del gasto total promedio mensual, los 6,091.00 y 3,918.00 representan el 6.9 y $7 \%$ respectivamente. Esto indicaría que las diferencias en el gasto en consumo de estos bienes, serían poco significativas desde el punto de vista del gasto promedio mensual de las familias de los estratos, y serían mucho más si éstas se buscaran a nivel de los distintos rangos de ingreso.

De esta forma, es significativo que quienes más gastan mensualmente en el pago de estos bienes, que como se anotó, es muy probable que hayan sido obtenidos y apropiados previamente a su pago, son las familias que perciben de 14 a más veces el salario mínimo en el estrato urbano medio, seguidas en volumen de gasto por las familias del estrato urbano privilegiado que ganan de tres a cuatro veces el salario mínimo, y las del estrato urbano medio que perciben entre 11.5 y 14 veces dicha cantidad. En adelante, quienes más gastan son las familias de otros niveles de ingreso del estrato urbano privilegiado, entre las que destacan las que perciben entre dos y tres, y hasta una vez el salario mínimo, que ocupan el $7 \mathrm{mo}$. y 8 vo. lugar en orden de importancia en el gasto.

En términos de prioridad de gasto, se tiene que quienes mayor proporción de su gasto en consumo destinan a este tipo de bienes son las familias del estrato urbano medio que perciben de 14 a más veces el salario mínimo, ya que destinan el $15.4 \%$ en contraposición a un 8.1 y un $3.5 \%$ de las de los estratos privilegiados y marginal respectivamente, lo que es coincidente con sus niveles absolutos de gasto. En segundo lugar, y al mismo nivel, se encuentran las familias de este mismo estrato y las del privilegiado que perciben entre 9 y 11.5 y entre tres y cuatro veces el salario mínimo respectivamente, que destinan el $13.3 \%$. Posteriormente, y destinando proporciones mayores del $9 \%$, se encuentran las familias del estrato urbano privilegiado que perciben ingresos entre dos y tres veces el salario mínimo con un $11.2 \%$; las que perciben entre 6.5 y 9 , y entre 11.5 y 14 veces tal cantidad con 9.8 y $9.3 \%$ respectivamente; y los del estrato urbano marginal que perciben entre 6.5 y 9 veces con un $9.1 \%$.

Por lo que respecta al grado de explicación del consumo por la estructura distributiva del ingreso observada, se tiene que desde el punto de vista de un análisis de regresión, el consumo autónomo realizado por las familias de los estratos urbanos privilegiado y medio es menor que el consumo promedio observado, en tanto que en el estrato marginal es mayor, aunque el nivel de gasto explicado por el nivel de ingreso sea en el 
primero y tercer estrato nulo e insignificante, mientras que en el estrato medio es explicado al $68 \%$, lo que se refleja en propensiones similares del $.02,4.6$ y $\cdot .05 \%$ respectivamente, que sólo son significativas al $95 \%$ de confianza para el estrato urbano medio. Cabe notar que el gasto en consumo autónomo mayor que el promedio notado en el estrato marginal, se traduce en una propensión a consumir negativa, que por tanto no puede ser explicada por la estructura del ingreso, en tanto que el gasto autónomo menor que el promedio observado en el estrato urbano medio se traduce en una elevada propensión a consumir, que por tanto es altamente explicada por la estructura distributiva del ingreso vigente, lo que podría explicarse a partir de las expectativas de mejoras en el nivel de ingreso (ciertas o infundadas) de las familias de este estrato urbano, que asociadas al generalizado sistema de ventas a crédito y a las aspiraciones de mejoramiento social relacionadas con la posesión de los bienes citados, son mayores.

\section{Servicios}

El gasto en consumo destinado a la adquisición de servicios, considera gastos en vivienda cuando ésta es rentada; servicios de mantenimiento del hogar como agua, electricidad, gas doméstico, petróleo, teléfono; servicios domésticos, tintorería y otros; servicios médicos y hospitalarios; de transporte, cuando no se posee vehículo particular; y servicios de cultura y esparcimiento que absorben un gasto familiar promedio de $35,657.00,18,394.00$ y $10,829.00$ pesos mensuales que significan el $27.3,20.7$ y $20.5 \%$ del gasto en consumo total de las familias de los estratos urbanos privilegiado, medio y marginal respectivamente.

El detalle de este gasto es muy importante porque refleja el otro lado de la moneda del gasto en bienes patrimoniales; ya que por ejemplo, en tanto que el gasto en vivienda refleja un gasto en servicios si ésta es rentada, o refleja un gasto en patrimonio si ésta es comprada en plazos. Este mismo caso es el del gasto en transporte.

De esta forma, el gasto promedio en servicio de vivienda de las familias del estrato urbano privilegiado es más alto que el promedio realizado por las familias de los otros estratos; aunque como puede ser fácilmente advertido, el pago de rentas no existe en la mayoría de las familias de los distintos niveles de ingreso del estrato urbano privilegiado, en tanto que el pago de renta en el estrato urbano medio sólo lo evitan las familias que ganan entre 9 y 14 veces el salario mínimo y las que ganan de 4 a 6.5 y de 9 a más veces dicha cantidad en el estrato urbano marginal.

A la vez, es significativo que mientras en el estrato urbano privilegiado las familias que ganan entre tres y cuatro y 14 y más veces el salario mínimo no tienen necesidad de pagar mensualidades de préstamos hipotecarios adquiridos para la construcción de su casa, así como tampoco 
pagar rentas, esta situación sólo se observa en las familias del estrato urbano marginal que ganan entre 9 y más de 14 veces el salario mínimo.

Por lo que respecta al transporte, el fácil acceso a los automóviles impide que se pueda distinguir de manera polar acerca de si poseen o no automóvil propio, ya que según los indicadores disponibles, todas las familias de todos los niveles de ingreso y de todos los estratos urbanos gastan tanto en transporte como servicio, como en transporte como patrimonio. Lo significativo en este caso es que, considerándolo como servicio, el transporte junto con los servicios de mantenimiento del hogar en el estrato urbano privilegiado; junto con los servicios médicos en el estrato urbano marginal, y junto con ambos en el estrato urbano medio, constituyen los principales rubros de gasto de las familias.

$\mathrm{Si}$ se considera un mayor detalle, sólo las familias que perciben ingresos equivalentes a 6.5 y 14 , y más veces el salario mínimo en el estrato urbano privilegiado, gastan en consumo de servicios un porcentaje mayor al promedio de su gasto en consumo total, observándose un comportamiento más o menos similar en los otros estratos. Sin embargo, cabe notar que estas oscilaciones en torno a la media no reflejan estructuras de gasto similares, ya que en tanto las familias del estrato urbano privilegiado que tienen ingresos hasta una vez el salario mínimo, destinan el $22.2 \%$ de su gasto a servicios; las de los estratos urbano medio y marginal destinan el 20.6 y el 20.3\% respectivamente, siguiendo este comportamiento todas las familias de los estratos urbanos clasificadas por rango de ingreso, excepto las que ganan entre dos y tres veces el salario mínimo, donde destinan a servicios el 17.9, 19.2 y $15.8 \%$ de su gasto en consumo total, cuando se pasa de un estrato a otro; y en las que perciben entre 11.5 y 14 y 14 y más veces el salario mínimo donde las familias destinan, cuando se pasa de un estrato a otro, $35.6,16.6$ y 17 y $30.2,28.5$ y $30 \%$ respectivamente; lo que indicaría, a manera de resumen en torno a comportamientos, que la mayoría de las familias de los mismos niveles de ingreso destinan una mayor proporción de su gasto al consumo de servicios, mientras mayor sea la cantidad de servicios urbanos con que cuente (como puede corroborarse en la observación del gasto en consumo en todos los servicios considerados), cuyos montos absolutos y proporcionales van de mayor a menor conforme se pasa de un estrato a otro. Igualmente, las familias del estrato medio urbano que perciben ingresos entre dos y tres veces el salario mínimo gastan más que las de los otros estratos, en tanto que las familias del estrato urbano marginal que perciben entre 11.5 y 14, y más veces dicha cantidad gastan más que sus homónimas de los otros estratos, dehido a los altos gastos en transporte que realizan, muy probablemente porque como sus ingresos provienen de actividades localizadas en el "otro lado" de la frontera, sus costos de desplazamiento en transporte público se incrementan para evitar las molestias e impertinencias en que se incurre por las largas "colas" para cruzar cuando se desplazan diariamente a su centro de trabajo en auto particular. 
Esto último se refleja en la división del gasto en transporte público y particular, donde se nota que de las familias que perciben el nivel de ingreso más alto, 14 y más veces el salario mínimo, las que más destinan el gasto de servicios de transporte público son las del estrato urbano marginal que destinan el $67.3 \%$ de su gasto en transporte, en contra de 48.9 y $32.1 \%$ que destinan las familias del mismo nivel de ingresos de los otros estratos urbanos.

Por lo que respecta al grado de explicación del gasto en consumo por la estructura imperante del ingreso, se tiene que desde el punto de vista del análisis de regresión, el consumo autónomo realizado en servicios por las familias de los distintos estratos urbanos es inferior al promedio, por lo que las propensiones a consumir son positivas y necesariamente mayores que las observadas en el gasto en consumo de otro tipo de bienes, ya que son del 9.4, 6.2 y $5 \%$ respectivamente, con un nivel de significancia en los parámetros de las ecuaciones del .01, .10 y .05 sucesivamente; esto es, un nivel de confianza del 99,90 y $95 \%$.

Ahora bien, el grado en que la estruetura del ingreso señalada explica la estructura del gasto y su posible tendencia, no en el tiempo sino en el lugar en caso de que hubiera cambios en la estructura distributiva del ingreso, es relevante y advierte sobre el hecho de que el gasto en consumo de servicios está muy influenciado por la estructura del ingreso, y que ante cambios en la misma, su consumo tendería a aumentar muy por encima del nivel actual, lo que podria lograrse con una política de mayor y mejor oferta de servicios y de protección del ingreso.

\section{Patrimonio}

Como ya se mencionó, este rubro considera todo aquello que se pueda considerar como bienes tangibles que posee una familia y que, a la vez que garantizan su seguridad y comodidad, brindan una economía que permite canalizar a otros bienes el gasto en consumo si es que los abonoso plazos han sido ya cubiertos en gran parte, o distraer recursos del gasto en otros bienes para pagar los altos enganches y primeros pagos que por lo regular implican sacrificios en el consumo global de la familia por inversiones que la misma considera, significarán grandes ahorros en el futuro.

Aquí cabe añadir a lo ya señalado, que el gasto que se realiza por las familias de todos los rangos de ingreso de todos los estratos considerados, en el auto particular, sus accesorios y su combustible, es muy superior al gasto mensual realizado en cubrir las hipotecas pactadas sobre la casa. Esto es muy significativo porque aunque parezca extraño, con las recientes devaluaciones y la escalada inflacionaria, las altas mensualidades de los "abonos" de la casa, se han reducido considerablemente, no así los gastos en autos e implementos que se ajustan a los cambiantes precios del mercado. 
En términos generales, sólo sería conveniente señalar que destacan por su elevado gasto promedio familiar en patrimonio, las familias del estrato urbano privilegiado que declararon percibir ingresos hasta el mínimo aunque destinan el $84 \%$ del mismo, al mantenimiento de su automóvil; lo cual explica éste y otros casos más adelante.

Por lo que respect a a la estructura del gasto estudiado desde el punto de vista del análisis de regresión, se tiene que al igual que en servicios, el gasto autónomo, es decir, el gasto realizado en la adquisición de bienes patrimoniales que se hace independientemente del nivel de ingreso, es menor que el gasto promedio mensual de las familias; de tal forma que ante cambios en la estructura distributiva del ingreso, se pueden esperar cambios positivos en el nivel de consumo de estos bienes en un $1.4,2.6$ y $2 \%$ respectivamente, del ingreso de las familias de cada estrato en el orden acostumbrado; a la vez que estos indicadores son significativos al 42, 86 y $81 \%$ respectivamente, pues estos datos indican el grado en que el gasto en consumo es explicado por la estructura del ingreso observada, cuyos parámetros son confiables en un nivel menor del $75 \%$ en el caso del estrato urbano privilegiado, y altamente confiable en los otros estratos al $99 \%$.

\section{Caracteristicas del consumo global}

Uno de los hallazgos más significativos de la encuesta, es que en todos los estratos urbanos considerados se observa la existencia de una transferencia de ingresos desde las familias de mayores hacia las de menores niveles de ingreso. El caso más visible es el de las familias que ganan hasta dos veces el salario mínimo en el estrato urbano privilegiado, donde su nivel de gasto promedio mensual de $152,965.00$ se encuentra 7.5 veces arriba del nivel de ingreso promedio mensual, lo que puede entenderse de dos formas: como una información mal proporcionada con base en un nivel de gasto deseado pero no alcanzado, o como una situación no contemplada por esquemas preconcebidos acerca del comportamiento del gasto de los consumidores. De esta forma, siguiendo este segundo criterio sería posible abrir una línea de indagación más profunda en torno a la transferencia de ingresos observada, que permite a las familias de menor nivel de ingresos en todos los estratos, pero principalmente en el urbano privilegiado, gozar de un cierto nivel de gasto y de bienestar que con todo, no elimina la peculiar falta de equidad en el gasto que se deriva de la peculiar falta de equidad en la distribución del ingreso, como ha sido observado ya en estudios anteriores. ${ }^{28}$ Además, una explicación adicional podría ser que a diferencia de los otros estratos, en éste el gasto en consumo se explica por otras variables adicionales al nivel de ingreso.

20 Barrera Basols, Dalia. "Tijuana, mito y realidad", Cuadernos politicos, México, ERA, oct.-die., Ne 26, pp. 90-101: Mungaray, Alejandro y Moetezuma, Patricia. 1984, "La disputa del mercado fronterizo. 1960-1983", Fistudios fronterizos, Mexicali, Instituto de Investigaciones Sociales, UABC, eneroabril, N³, pp. 89.111; Moctezuma, Patricia y Mungaray, Alejandro. 1985, "Ganancias, devaluación y salarios en la frontera norte de México", Economía informa, México, Facultad de Economía, UNAM, No 124, pp. 27-31; Herzog, Larry. 1984, "The two faces of Tijuana", San Diego Newsline, April 4, Vol. 7. Ne25, pp. 1 y 5 . 
Una segunda observación resulta ser de tipo más obvio. Se trata de que conforme aumenta el tamaño del ingreso mensual promedio, aumenta el tamaño del gasto mensual promedio, pero también el nivel de ahorro, lo que permite afirmar que el nivel de holgura en el bienestar familiar aumenta conforme se pasa en la observación de un nivel de ingreso a otro.

Por último, es notorio que en todos los estratos urbanos considerados, el consumo autónomo tal como se ha definido, es menor que el gasto promedio observado en los resultados de la encuesta; lo que habla en términos generales del hecho, de que ciertas modificaciones en la estructura imperante del ingreso, ayudarían a incrementar el nivel de gasto en consumo, ya que las propensiones a consumir estimadas son del 11.7, 20.5 y del $15 \%$ respectivamente, siendo altamente significativo el grado en que estos indicadores del consumo son explicados por la estructura del ingreso al 52,83 y $87 \%$ en cada estrato urbano considerado respectivamentef, y donde el nivel de significancia de los parámetros consumo autónomo y propensión a consumir tienen el $.25, .01$ y .01 de significancia; esto es, son confiables al $75 \%$ en caso del estrato urbano privilegiado y al $99 \%$ en los otros estratos.

\section{CONCLUSIONES}

En primer término, se puede notar que sólo se observa una propensión homogénea a consumir ante variaciones en la distribución del ingreso, en bienes perecederos primarios, y duraderos tradicionales de los estratos urbanos medio y marginal y que, ante la gama de propensiones diferentes, la distribución del ingreso entre los consumidores es sumamente heterogénea, por lo que resulta dificil afirmar que las funciones de consumo globales sean unas funciones estables.

En segundo lugar, se nota que salvo en el caso de los servicios, las propensiones a consumir ante cambios redistributivos del ingreso son más altas en el estrato urbano medio, aunque el gasto autónomo en consumo sea en todos los bienes menor que en el estrato urbano privilegiado, y mayor, salvo en los bienes duraderos modernos, que en el estrato urbano marginal.

En tercer lugar, se puede notar que la estructura absoluta del gasto no coincide con la estructura porcentual del mismo, ya que en términos generales es típico que el mayor gasto de las familias de mayores y menores ingresos del estrato urbano privilegiado signifique una proporción de su gasto total menor que la proporción que significa un gasto mayor de las familias de mayores y menores ingresos de los estratos urbanos medio y marginal.

La inclusión de la variable "riqueza patrimonial" ha mostrado que pese a que la propensión a consumir sería mayor en el estrato urbano 
marginal que en los otros, ante cambios en la distribución del ingreso, los gastos autónomos que se realizan son mayores en el estrato urbano privilegiado, aunque en todos los casos son exiguos e incongruentes con el estado actual de los precios de la venta y renta de los inmuebles, lo que podría ser explicado en virtud del repentino cambio en las condiciones de vida de la población ante la devaluación y la acelerada inflación que se vive desde 1982.

Un elemento importante que no ha sido considerado, es la confrontación del comportamiento del consumo ante los mismos bienes y servicios, tanto cuando son de origen nacional como cuando son de origen extranjero. Sin embargo, aquí conviene añadir, dado el cambio constante observado en las corrientes de consumo, que el consumidor tijuanense se orienta hacia uno u otro mercado, en función del tipo de cambio que le permita acceder a los bienes y servicios que requiere. En particular, se podría abundar que ciertos estratos de la población de Tijuana soportan los altos precios en el mercado local hasta en tanto las presiones inflacionarias de la economía mexicana no eleven sustancialmente la diferencia entre tipo de cambio real y nominal, y resulte mejor acudir de nuevo al comercio estadounidense, siempre buscando proteger al máximo su nivel de ingreso disponible en condiciones geográficas de privilegio que les permite, según sea el caso, una gran movilidad, sólo permisible a quienes posean la visa de cruce a los Estados Unidos, que constituye entonces un valor importante para el consumidor. ${ }^{29}$

\section{AGRADECIMIENTOS}

Se agradecen los comentarios y apoyos técnicos de Manuel M. Esparza, Froylán Esparza y Patricia Moctezuma, profesores de la Universidad Autónoma de Baja California; de Ramón E. Luque, funcionario de la Secretaría de Organización, Programación y Presupuesto del Gobierno del Estado de Baja California; y de Bernardo GonzálezAréchiga, director del Departamento de Economía del Colegio de la Frontera Norte. Asimismo, se agradece el soporte financiero del XI Ayuntamiento de Tijuana y de la Universidad Autónoma de Baja California, otorgado entre marzo de 1984 y agosto de 1985 para el desarrollo total de la investigación. ${ }^{30}$

\footnotetext{
${ }^{29}$ González-Aréchiga. Bernardo. Utilidad y medición de indices de costo de la vida e inflación en una economía fronteriza: una instancia de redistribución sistemática del bienestar de clase, Tijuana, Instituto de Investigaciones Económicas y Sociales, UABC, (Cuadernos de Economía, Serie I, N²5), 1986. p. 26.

${ }^{30}$ Mungaray, Alcjandro y Moctczuma Patricia. Distribución del ingreso, comportamiento del consumo y precios en el área urbana de Tijuana, B.C., Tijuana, Instituto de Investigaciones Económicas y Sociales, UABC, agosto 1985, 225 pp.
} 


\section{BIBLIOGRAFIA}

BAROKAS, Rifat y Vargas, Alvaro E. 1981, "Estudio de mercado y comercialización", Curso sobre formulación y evaluación de proyectos, México, FONEP, 314 pp.

BARRERA Basols, Dalia. 1980, "Tijuana, mito y realidad", Cuadernos políticos, México, ERA, oct.-dic., № 26, pp. 90-101.

BRANSON, W.H. 1981, Teoría y política macroeconómica, México, FCE.

CORTES, Fernando. 1981, Algunos problemas de formalización y estimación de modelos de regresión con variables cualitativas aplicadas a la investigación social, México, El Colegio de México (Cuadernos del CES 29).

DILLARD, Dudley. 1971, La teoría económica de John Maynard Keynes, Madrid, Aguilar, 9a. ed.

DIULIO, Eugene. 1981, Macroeconomía, México, McGraw Hill (Shaum).

EDWARDS, Allen L. 1976, An introduction to linear regression and correlation, San Francisco, W.H. Freeman Company.

FRIEDMAN, Milton \& Rose. 1981, Free to choose, New York, Avon Books.

FRIEDMAN, Milton. 1983, "La General Theory como estímulo para la investigación económica”, en Lekachman 1983.

GONZALEZ-ARECHIGA, Bernardo. 1986, Utilidad y medición de índices de costo de la vida e inflación en una economía fronteriza: una instancia de redistribución sistemática del bienestar de clase, Tijuana, Instituto de Investigaciones Económicas y Sociales, UABC, (Cuadernos de Economía, Serie I, № 5), 27 pp.

HANSEN, Alvin. 1978, Guía de Keynes, México, FCE. 6a. reimp. 1983, "La función de consumo como contribución a la teoría económica", en Lekachman 1983.

HEILBRONER, Robert. 1962, The making of economic society, Englewood Cliffs, Prentice Hall.

HERZOG, Larry. 1984, "The two faces of Tijuana", San Diego Newsline, San Diego, april 4, Vol. 7, № 25, pp. 1 y 5.

HICKS, J.H. 1958, Revisión de la teoría de la demanda, México, FCE.

KEYNES, J.M. 1979, La teoría general de la ocupación, el interés y el dinero, México, FCE, 9a. reimp.

KIM, Jae-On y Kohout, Frank J. 1981, "Múltiple regression analysis; subprogram regression", varios, SPSS. Statistical Package for the Social Sciences, Chicago, McGraw Hill, 2a. ed.

LEKACHMAN, Robert (Comp.), 1983, John Maynard Keynes, Madrid, Sarpe.

LIPSEY, Richard G. 1974, Introducción a la economía positiva, Barcelona, Vicens-Vires, 9a. ed. 
LUSTIG, Nora. 1981, Distribución del ingreso y crecimiento en México. Un análisis de las ideas estructuralistas, México, El Colegio de México.

MOCTEZUMA, Patricia y Mungaray, Alejandro. 1985, "Ganancias, devaluación y salarios en la frontera norte de México", Economía Informa, México, Facultad de Economía, UNAM, enero, № 124, pp. 27-31.

... "La disputa del mercado fronterizo. 1960-1983", Estudios Fronterizos, Mexicali, Instituto de Investigaciones Sociales, UABC, eneroabril, No 3, pp. 89-111.

... 1985, Distribución del ingreso, comportamiento del consumo y precios en el área urbana de Tijuana, B. C., Tijuana, Instituto de Investigaciones Económicas y Sociales, UABC, agosto (reporte terminal de programa de investigación), $225 \mathrm{pp}$.

SABAU, Hernán. 1982, El método econométrico. Una visión intuitiva, México, CIDE.

SUKHATME, Pandurang V. 1962, Teoría de encuestas por muestreo con aplicaciones, México, FCE, 2a. ed. 


\section{ANEXO ESTADISTICO}

CUADRO 1. Gasto familiar por nivel de ingresos estrato urbano en Tijuana

\begin{tabular}{|c|c|c|c|c|c|c|c|c|c|c|c|c|c|c|c|c|}
\hline Tipo de & & & & & & & & & RYICI & & & & & ATRIMON & & \\
\hline $\begin{array}{l}\text { Estrato de } \\
\text { ingreso }\end{array}$ & A P P & B P T & B D T & В D M & viy. & M.H. & S.M. & S.T. & S.A. & RyE & TOTAL. & viv. & T.P. & Totral. & I.D. & TOYTAL. \\
\hline
\end{tabular}

ESTRATO URBANO PRIVILEC IA D O

\begin{tabular}{|c|c|c|c|c|c|c|c|c|c|c|c|}
\hline $0-20,400$ & 36,825 & 21,488 & 30,563 & 11,533 & & 18,141 & 6,466 & 3,691 & 2,906 & 3,075 & $34,274^{*}$ \\
\hline $20.401-40.300$ & 20.230 & 15.264 & 21.781 & 9.416 & 2.437 & 6,493 & 6,258 & 4,006 & 1.718 & 3,183 & 24,095 \\
\hline $40,801-61,200$ & 27,585 & 12,244 & 23,100 & 11,545 & 0 & 5,082 & 4,495 & 3,622 & 1,887 & 3,312 & 18,398 \\
\hline $61,201-81,600$ & 27,163 & 13,045 & 25,804 & 16,708 & 0 & 5,618 & 6,662 & 11,585 & 1,781 & 4,839 & 30,485 \\
\hline $81,601-132,600$ & 27,143 & 11,890 & 23,117 & 7,874 & 1,500 & 9,418 & 6,606 & 8,907 & 1.699 & 4.320 & 32.450 \\
\hline $132,601-183,600$ & 24,346 & 9,592 & 23,276 & 12,541 & 0 & 17,803 & 7,861 & 9,413 & 2,259 & 0,765 & 44,101 \\
\hline $183.601-234.600$ & 27.070 & 12.760 & 26,405 & 3.040 & 0 & 13.255 & 5.012 & 8,340 & 1,412 & 4,677 & 32,696 \\
\hline $234,601-285,600$ & 26,222 & 14,292 & 23,000 & 13,321 & 0 & 16,992 & 10,678 & 13,635 & 1,991 & 7,607 & 50,903 \\
\hline 285,601 y max & 36,483 & 16,599 & 34,639 & 13,860 & 0 & 26,525 & 8,342 & 8,123 & 2,776 & 0,141 & 51,907 \\
\hline Promedio & 28,753 & 14,045 & 26.518 & 11,393 & 591 & 12.421 & 7.609 & 8.437 & 1.856 & 4.743 & 35.657 \\
\hline
\end{tabular}

\begin{tabular}{|c|c|c|c|c|c|c|c|c|c|c|c|}
\hline $0-20.400$ & 22,846 & 11.396 & 12.697 & 5.311 & 16 & 3.767 & 4.243 & 4,588 & 805 & 1,490 & 14,909 \\
\hline $20,401-40,800$ & 24,094 & 12,556 & 14,753 & 4,716 & 800 & 4,707 & 4.709 & 3,612 & 874 & 1.650 & 22,255 \\
\hline $40.801-61,200$ & 28,054 & 14,203 & 16,785 & 5,827 & 552 & 5,574 & 4,856 & 3,009 & 1,061 & 2,204 & $16,429^{\circ}$ \\
\hline $61,201-81,600$ & 29,745 & 13,408 & 16,021 & 5,223 & 248 & 6,402 & 4,809 & 3.816 & 1.260 & 2.183 & 18.726 \\
\hline $81,601 \cdot 132,600$ & 29,615 & 13,574 & 18,278 & 6,510 & 60 & 6,399 & 6,363 & 4,182 & 1,185 & 2,780 & 20,909 \\
\hline $132,601-183,600$ & 30.089 & 14.923 & 21,846 & 6,005 & 595 & 7,575 & 6,775 & 7,344 & 1,566 & 3,373 & 27,228 \\
\hline $183,601-234,600$ & 28,563 & 13,900 & 23,812 & 16,703 & 0 & 6,182 & 5,607 & 12,621 & 1,490 & 4,169 & 30.069 \\
\hline $234,601-285,600$ & 31,229 & 16,138 & 19,633 & 4,900 & 0 & 4,966 & 3,825 & 2,583 & 958 & 4,225 & 16,557 \\
\hline 285,601 y mass & 32,274 & 15,140 & 24,584 & 24,183 & 86 & 12,886 & 8.915 & 14.051 & 1.932. & 6.807 & 44.677 \\
\hline Promedio & 26,757 & 13,059 & 15,948 & 6,091 & 302 & 5,512 & 5,079 & 4,218 & 1,085 & 2,198 & 18,394 \\
\hline
\end{tabular}

$\begin{array}{rrrrl}2,750 & 14,450 & 17,202 & 28 & 152,965 * \\ 0 & 9,116 & 9,118 & 222 & 108,239 \\ 225 & 9,555 & 9,782 & 125 & 102,779 \\ 0 & 10,629 & 10,629 & 196 & 125,030 \\ 3.277 & 13.550 & 16.028 & 350 & 119,652 \\ 519 & 16,173 & 16,693 & 250 & 133,168^{*} \\ 975 & 11,857 & 12,875^{*} & 456 & 115,330 \\ 589 & 13,650 & 14,241 & 771 & 142,750 \\ 0 & 17,150 & 17,152 & 988 & 171,622 \\ 939 & 12,993 & 13.993 & 940 & 130,639\end{array}$

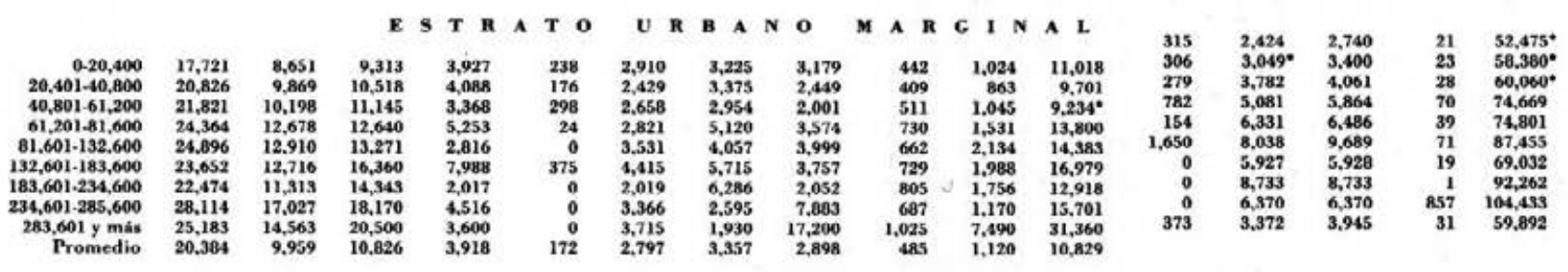

NOTA: Los totales indicades con "punden no coincidir con sus componentes debido a redondeo de ajuste.

FUENTE: Eneuesta soeioeconómiea del ingreas-kasto realizado por el IIES-UABC, junio 1984.

\begin{tabular}{|c|c|c|c|c|}
\hline 1,488 & 4,566 & $5,845^{\circ}$ & 47 & $74,201^{\circ}$ \\
\hline 1.092 & 6.772 & 7.865 & 61 & $87,057^{\circ}$ \\
\hline 1,168 & 6,532 & 7,701 & 43 & $89,267^{\circ}$ \\
\hline 1,381 & 7,886 & 9,268 & 94 & 92,483 \\
\hline 2,240 & 9.584 & 11.825 & 117 & 100,888 \\
\hline 2,161 & 10,520 & 12,682 & 50 & 112,823 \\
\hline 750 & 11.396 & 12,147 & 171 & 125,395 \\
\hline 3,250 & 7,750 & 11,001 & 3 & $99,461^{\circ}$ \\
\hline & 14,660 & $\begin{array}{l}15,478 \\
1580\end{array}$ & 703 & 156,904 \\
\hline 1.253 & 7.122 & 8.375 & 76 & 88.700 \\
\hline 315 & 2,424 & 2,740 & 21 & $52,475^{*}$ \\
\hline & $3.049^{\circ}$ & 3,400 & 23 & $58.380^{\circ}$ \\
\hline 279 & 3,782 & 4,061 & 28 & $60,060^{\circ}$ \\
\hline 782 & 5,081 & 5,864 & 70 & 74,669 \\
\hline 154 & 6.331 & 6.486 & 39 & 74,801 \\
\hline 1,650 & 8,038 & 9,689 & 71 & 87,455 \\
\hline 0 & 5.927 & 5.928 & 19 & 69.032 \\
\hline 0 & 8,733 & 8,733 & 1 & 92,262 \\
\hline & 6.370 & 6,370 & 857 & 104,483 \\
\hline 373 & 3.372 & 3.945 & 31 & 59.892 \\
\hline
\end{tabular}


CUADRO 2. Distribución porcentual del gasto familiar por nivel de ingreso, tipo de consumo y estrato urbano en Tijuana.

\begin{tabular}{|c|c|c|c|c|c|c|c|c|c|c|c|c|c|c|c|c|}
\hline Consumo & 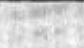 & & & $2=$ & & & \multicolumn{5}{|c|}{ SERVICIOS } & \multicolumn{5}{|c|}{ PATRIMONIO } \\
\hline \begin{tabular}{|l} 
Estrato \\
ingreso
\end{tabular} & $B \times P$ & BP & BD 1 & 800 & VIV, & М.H. & S.M. & S.T. & S.A. & RyE & TOTAL & vIv. & T.P. & TOTAL & I.D. & TOTAL. \\
\hline
\end{tabular}

ESTRATO URBANO PRIVILEGIA DO

$\begin{array}{rrr}0.20,400 & 24.07 & 14.05 \\ 20,481 \cdot 40,800 & 26.56 & 13.73 \\ 40,801-6.200 & 26.84 & 11.91 \\ 61,201-81,000 & 21.72 & 10.43 \\ 81,601-132,600 & 22.68 & 9.94 \\ 132,601 \cdot 103,600 & 18.58 & 7.32 \\ 183,601-234,600 & 23.47 & 11.06 \\ 243,6011.285,600 & 18.37 & 10.01 \\ 285,601 \text { y min } & 21.26 & 9.67 \\ \text { Promedio } & 22.01 & 10.75\end{array}$

\begin{tabular}{|c|c|c|}
\hline 1.90 & 7.54 & .00 \\
\hline 20.12 & 8.70 & 2.25 \\
\hline 22.47 & 11.23 & .00 \\
\hline 21.44 & 13.36 & .00 \\
\hline 19.32 & 6.58 & 1.25 \\
\hline 17.76 & 9.75 & .00 \\
\hline 22.89 & 3.33 & .00 \\
\hline 16.11 & 9.33 & .00 \\
\hline 20.18 & 8.08 & .00 \\
\hline 20.30 & 8.72 & .45 \\
\hline
\end{tabular}

$\begin{array}{rrr}11.86 & 4.23 & 2.41 \\ 6.00 & 5.78 & 3.70 \\ 4.94 & 4.37 & 3.52 \\ 4.49 & 5.33 & 9.27 \\ 7.87 & 5.52 & 7.41 \\ 13.59 & 6.00 & 7.18 \\ 11.49 & 4.35 & 7.23 \\ 11.90 & 7.48 & 9.55 \\ 15.45 & 4.86 & 4.73 \\ 9.51 & 5.82 & 6.46\end{array}$

$\begin{array}{llll}1.66 & 2.01 & 22.17 & 1.90 \\ 1.89 & 2.94 & 22.26 & .00 \\ 1.84 & 3.22 & 17.89 & .22 \\ 1.42 & 3.87 & 23.48 & .90 \\ 1.42 & 3.61 & 27.11 & 2.74 \\ 1.72 & 5.16 & 33.65 & .45 \\ 1.22 & 4.06 & 28.35 & .85 \\ 1.39 & 5.33 & 35.65 & \\ 1.62 & 3.58 & 30.24 & .60 \\ 1.42 & 3.63 & 27.29 & .72\end{array}$

U $R$ R $\quad$ A $A$ N $\quad$ O

M E D I 0

0-20,400

$20,401.40,800$

$\$ 0.801 \cdot 61.200$

$21,201.81,600$

$132,601-183,600$

$183,601 \cdot 234,600$

$234,601 \cdot 285,600$

5,601 y mán
Promedio

$\begin{array}{llll}31.54 & 15.21 & 16.91 & 7.33\end{array}$

$\begin{array}{ll}.02 & 5.20 \\ .38 & 5.8 \\ .62 & 6.27 \\ .27 & 6.92 \\ .06 & 6.34 \\ .53 & 6.71 \\ .00 & 4.93 \\ .00 & 4.99 \\ .06 & 8.2 \\ .34 & 6 .\end{array}$

\begin{tabular}{rr}
5.86 & 6.33 \\
5.84 & 4.51 \\
6.41 & 3.35 \\
5.20 & 4.13 \\
6.31 & 4.15 \\
6.00 & 6.51 \\
4.97 & 10.06 \\
3.85 & 2.60 \\
5.68 & 8.95 \\
5.73 & 4.76 \\
\hline
\end{tabular}

$\begin{array}{llll}1.11 & 2.06 & 20.58 & 2.06 \\ 1.08 & 2.05 & 19.69 & 1.35 \\ 1.18 & 2.45 & 19.22 & 1.30 \\ 1.37 & 2.36 & 20.25 & 1.49 \\ 1.17 & 2.76 & 20.79 & 2.22 \\ 1.39 & 2.99 & 24.13 & 1.92 \\ 1.19 & 3.32 & 23.97 & .60 \\ .96 & 4.25 & 16.65 & 3.2 \\ 1.23 & 4.34 & 28.47 & .51 \\ 1.22 & 2.48 & 20.74 & 1.4\end{array}$

$\begin{array}{rrrrr}80 & 9.45 & 11.25 & \\ 00 & 8.42 & 8.42 & \\ .22 & 9.30 & 9.52 & .19 \\ 00 & 8.50 & 8.50 & \\ 74 & 11.32 & 14.06 & \\ .40 & 12.34 & 12.74 & \\ 85 & 9.65 & 10.50 & \\ 41 & 9.56 & 9.97 & \\ 00 & 9.99 & 9.99 & \\ .78 & \end{array}$

9.94

10.66

$\begin{array}{llll}.23 & 15.81 & 18.69 & 6.43\end{array}$

$\begin{array}{llll}32.16 & 14.50 & 17.32 & 5.65 \\ 29.35 & 13.45 & 18.12 & 6.45\end{array}$

$\begin{array}{lllr}26.67 & 13.23 & 19.36 & 5.32 \\ 22.78 & 11.09 & 19.01 & 13.32\end{array}$

$\begin{array}{llll}31.40 & 16.23 & 19.74 & 4.93 \\ & 9.64 & 15.66 & 15.37\end{array}$

$\begin{array}{rr}20.56 & 9.64 \\ 30.16 & 14.72\end{array}$

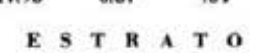

U R B A N o

$M A R G \perp N A L$

0-20.400

$20,401-40,800$

40,801-61,200

$81,601-132,600$

32,601-183,600

$4,601-285,600$

285,601 y mas

Promedio
Promedio tolal

$\begin{array}{llll}\mathbf{3 2 . 7 9} & 15.80 & 18.79 & 7.23 \\ 35.67 & 16.90 & 18.01 & 7.00 \\ \mathbf{3 6 . 3 3} & 16.98 & 18.55 & 5.56 \\ \mathbf{3 2 . 6 3} & 16.96 & 16.93 & 7.04 \\ \mathbf{3 2 . 2 8} & 17.26 & 17.74 & \mathbf{3 . 7 7} \\ \mathbf{2 7 . 0 4} & 14.54 & 18.71 & 9.3 \\ \mathbf{3 2 . 5 6} & 16.39 & 20.78 & 2.94 \\ 30.47 & 18.45 & 19.69 & \mathbf{4 . 9 0} \\ \mathbf{2 4} .11 & 13.94 & 19.63 & \mathbf{3 . 4 5} \\ \mathbf{3 4 . 0 2} & 16.62 & 18.07 & 6.54 \\ \mathbf{3 0 . 7 2} & 15.01 & 18.34 & \mathbf{6 . 9 9}\end{array}$

$\begin{array}{lll}7.23 & .44 & 5.36 \\ 7.00 & .30 & 4 . \\ 5.56 & .30 & 4.4 \\ 7.04 & .03 & 3.7 \\ 3.77 & .00 & 4.7 \\ 9.3 & .43 & 5.05 \\ 2.94 & .00 & 2.9 \\ 4.90 & .00 & 3.65 \\ \mathbf{3 . 4 5} & .00 & 3.56 \\ 6.54 & .29 & 4.6 \\ 6.99 & .33 & 5.9\end{array}$

$\begin{array}{llr}5.36 & 5.94 & 5.85 \\ 4.16 & 5.78 & 4.20 \\ 4.43 & 4.92 & 3.33 \\ 3.78 & 6.86 & 4.79 \\ 4.72 & 5.42 & 5.35 \\ 5.05 & 6.53 & 4.30 \\ 2.93 & 9.11 & 2.97 \\ 3.65 & 2.81 & 8.54 \\ 3.56 & 1.85 & 16.47 \\ 4.67 & 5.61 & 4.84 \\ 5.99 & 5.69 & 5.04\end{array}$

$\begin{array}{rll}.82 & 1.89 & 20.30 \\ .70 & 1.18 & 16.62 \\ .85 & 1.74 & 15.77 \\ .90 & 2.05 & 18.49 \\ .89 & 2.85 & 19.23 \\ .83 & 2.27 & 19.41 \\ 1.17 & 2.55 & 18.73 \\ .75 & 1.27 & 17.02 \\ .98 & 7.17 & 30.03 \\ .81 & 1.87 & 18.09 \\ 1.07 & 2.37 & 20.49\end{array}$

$\begin{array}{rr}.58 & 4.46 \\ .53 & 5.22 \\ .47 & 6.30 \\ 1.05 & 6.80 \\ .21 & 8.46 \\ 1.89 & 9.19 \\ .00 & 8.59 \\ .00 & 9.46 \\ .00 & 8.01 \\ .62 & 5.96 \\ .96 & 7.38\end{array}$

$\begin{array}{rrr}5.04 & .04 & 100 \\ 5.75 & .04 & 100 \\ 6.77 & .05 & 100 \\ 7.85 & .09 & 100 \\ 8.67 & .05 & 100 \\ 11.08 & .08 & 100 \\ 8.59 & .03 & 100 \\ 9.46 & .00 & 100 \\ 8.01 & .82 & 100 \\ 6.58 & .05 & 100 \\ 8.4 & .10 & 100\end{array}$

FLENTE: Fnrursta secioeconómica de ingremo-gasto reatizado por el IIES.UABC, junio 1984 
CUADRO 3. Análisis de regresión. Consumo con ingreso

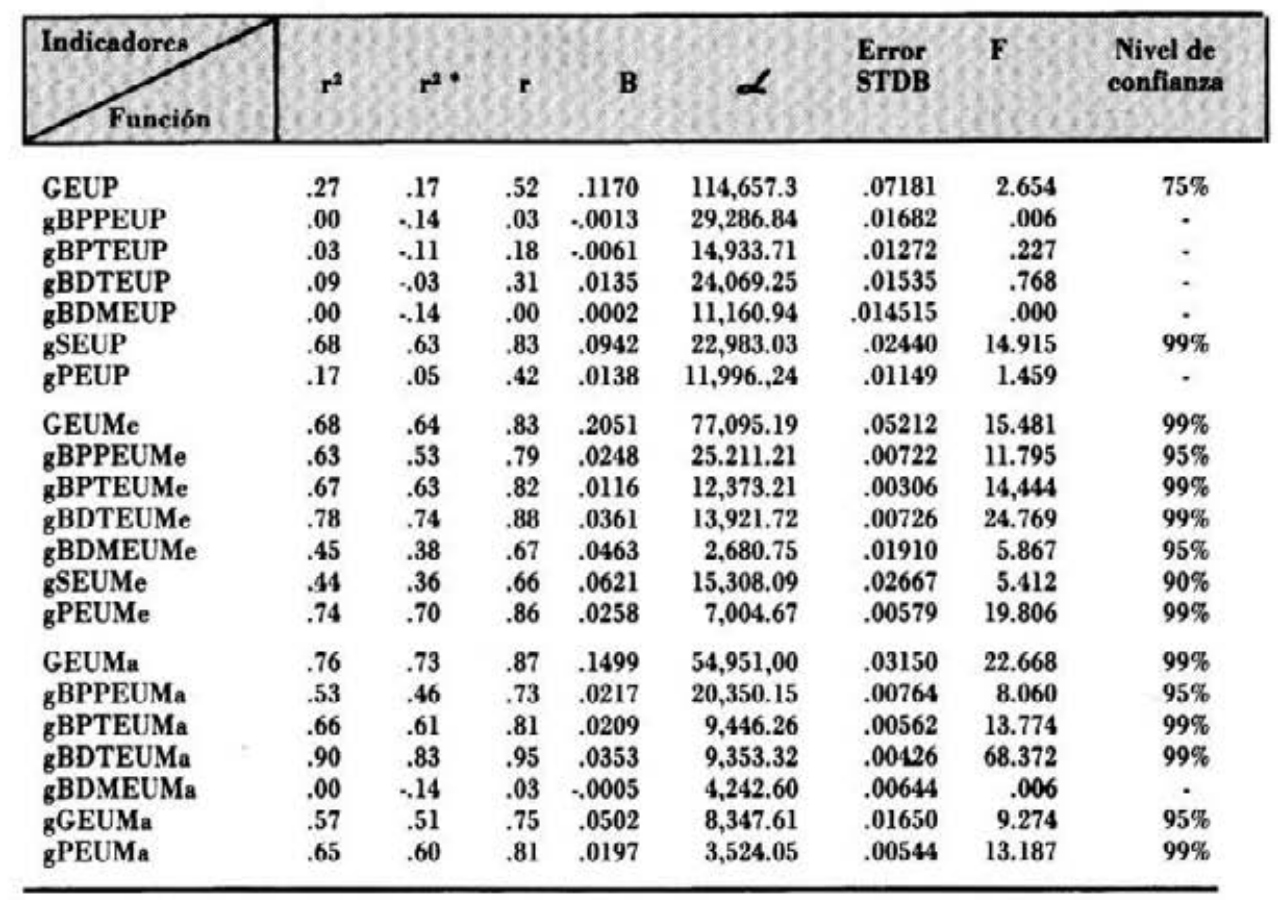

NOTA: Los EUP, EUMe y EUMa se refieren a estratos urbanos privilegiado, medio y marginal respectivamente: $\mathrm{G}=$ gasto total; $\mathrm{gBPP}=$ gasto en bienes perecederos primarios; $\mathrm{gBPT}=$ gasto en bienes perecederos tradicionales; $\mathrm{gBDT}=$ gasto en bienes duraderos tradicionales: $\mathrm{gBDM}=$ gasto en bienes duraderos modernos; $\mathrm{gS}=$ gasto en servicios; y gP= gasto en patrimonio.

FUENTE: Encuesta socioeconómica de ingreso-gasto, IIES-UABC, junio 1984.

NOTA: Todas las explicaciones econométricas de los parámetros de las ecuaciones y de los coeficientes y pruebas estadísticas en este caso de F, han sido realizados con base en Kim y Kohout 1981:323-328. 
CUADRO 4. Distribución del gasto en transporte en público y privado.

\begin{tabular}{|c|c|c|c|c|c|c|c|c|c|c|c|c|c|c|c|c|}
\hline \multirow{3}{*}{$\begin{array}{l}\text { Nivel de } \\
\text { Ingreso } \\
\end{array}$} & \multirow{3}{*}{ Indicador } & \multicolumn{5}{|c|}{ Estrato urbano privilegiado } & \multicolumn{5}{|c|}{ Estrato urbano medio } & \multicolumn{5}{|c|}{ Estrato urbano marginal } \\
\hline & & \multicolumn{2}{|c|}{ Particular } & \multicolumn{2}{|c|}{\begin{tabular}{|l|} 
Público \\
\end{tabular}} & \multirow{2}{*}{\begin{tabular}{|c|} 
Total \\
ARS. \\
\end{tabular}} & \multicolumn{2}{|c|}{ Particular } & \multirow{2}{*}{$\begin{array}{l}\text { Páblico } \\
\text { ABS. } \\
\end{array}$} & \multirow{2}{*}{\begin{tabular}{|l|} 
Total \\
REL. \\
\end{tabular}} & \multirow{2}{*}{ ABS. } & \multirow{2}{*}{\begin{tabular}{|c|} 
Particular \\
ABS. \\
\end{tabular}} & \multicolumn{2}{|c|}{ Público } & \multicolumn{2}{|c|}{ Total } \\
\hline & & ABS. & REL. & ABs. & REI- & & ABS: 1 & REL & & & & & REL. & ARS. & REI. & ABS. \\
\hline 0 & 20,400 & 14,450 & 79.7 & 3,691 & 20.3 & 318,1 & 4,556 & 49.8 & 4.588 & 50.2 & 9,144 & 2,424 & 43.3 & 3,1 & 56.7 & 5,603 \\
\hline 20,401 & 40,800 & 9,116 & 69.5 & 4,006 & 30.9 & 13 , & 6,772 & 65.0 & 3,642 & 35.0 & 10,414 & 3,049 & 55.5 & 2,449 & 44.5 & 5,498 \\
\hline 40,801 & 61,200 & 9,555 & 72.5 & 3,672 & 27.5 & 13,177 & 6,532 & 68.5 & 3,009 & 31.5 & 9,541 & 3,782 & 65.4 & 2,001 & 39.6 & 5,783 \\
\hline 61,201 & 81,600 & 10,629 & 47.8 & 11,585 & 52.2 & 22,214 & 7,886 & 67.4 & 3,816 & 32.6 & 11,702 & 5,081 & 58.7 & 3,574 & 41.3 & 8.655 \\
\hline 81,601 & 132,600 & 13,550 & 60.3 & 8,907 & 39.7 & 22,457 & 9,584 & 69.6 & 4,182 & 30,4 & 13,766 & 6.331 & 61.3 & 3,999 & 38.7 & 10,330 \\
\hline 132,601 & 183,600 & 16,173 & 63.2 & 9,413 & 36.8 & 25,586 & 10,520 & 58.9 & 7,344 & 41.1 & 17,864 & 8,038 & 68.2 & 3,757 & 31.8 & 11,795 \\
\hline 183,601 & 234,600 & 11,857 & 58.7 & 8,340 & 41.3 & 20,197 & 11,396 & 47.5 & 12,621 & 52.5 & 24,017 & 5,927 & 74.3 & 2,052 & 25.7 & 7,979 \\
\hline 234,601 & 285,600 & 13,650 & 50.0 & 13.635 & 50.0 & 27,285 & 7.750 & 75.0 & 2.583 & 25.0 & 10.333 & 8.733 & 52.6 & 7,883 & 47.4 & 16.616 \\
\hline 285,601 & $y$ más & 17,150 & 67.9 & 8,123 & 32.1 & 25,273 & 14,669 & 51.1 & 14,051 & 48.9 & 28,720 & 8,370 & 32.7 & 17,200 & 67.3 & 25,570 \\
\hline \multicolumn{2}{|c|}{ Promedio } & 12,993 & 60.6 & 8,437 & 39.4 & 21,430 & 7,122 & 62.8 & 4,218 & 37.21 & 1,340 & 3,572 & 55.2 & 2,898 & 44.8 & 6,470 \\
\hline
\end{tabular}

FUENTE: Encuesta socioeconómica de ingreso-gasto realizada por el IIES.UABC, junio 1984. 